\title{
A agenda do Legislativo Federal para as políticas curriculares no Brasil (1995-2007)*
}

Rosimar de Fátima Oliveira

Universidade Federal de Viçosa

Correspondência:

Rosimar de Fátima Oliveira

Universidade Federal de Viçosa

Av. Peter H. Rolfs, s/n, Campus, DPE

36570-000 - Viçosa - MG

e-mail: rosimar@ufv.br

\section{Resumo}

Considerando a organização do Congresso Nacional instituída a partir da Constituição Federal de 1988, este trabalho tem o objetivo de investigar o papel do Poder Legislativo na formulação das políticas curriculares no Brasil, destacando e discutindo a agenda proposta no âmbito desse Poder para as matérias sobre esse tema. Para consecução desse objetivo, foram identificadas todas as proposições sobre educação apresentadas e concluídas no processo legislativo durante as 50a $5^{\text {a }}$ e 52a legislaturas (1995-2007), analisando-se, entre estas, aquelas que tomam como objeto o currículo escolar. Dessa maneira, o trabalho analisa o processo legislativo de 29 proposições sobre currículo escolar, 3 das quais transformadas em norma jurídica. Conclui-se que o Poder Legislativo apresenta um fraco poder de agenda em relação às políticas curriculares, limitando suas propostas à criação ou à modificação de disciplinas escolares. $\mathrm{Na}$ concepção de política curricular expressa por meio das proposições apresentadas, é como se o currículo escolar se instituísse de fora para dentro das escolas, pelo somatório desarticulado de disciplinas pretensamente importantes para a minimização das mazelas sociais. Não são preocupações de tais projetos os objetivos precípuos da instituição escolar, mas as próprias problemáticas sociais que os inspiraram. Desconsideram o contexto da prática, revelando procedimentos para os quais o texto da política curricular parece fazer sentido em si mesmo, fora dos processos de recontextualização e hibridismo fundamentais para o entendimento das políticas curriculares como políticas culturais.

\section{Palavras-chave}

Política educacional - Políticas curriculares - Disciplinas escolares - Poder Legislativo - Legislação Educacional. 


\section{The agenda of the Federal Legislative for curriculum policies in Brazil (1995-2007)*}

Rosimar de Fátima Oliveira

Universidade Federal de Viçosa

Contact:

Rosimar de Fátima Oliveira Universidade Federal de Viçosa Av. Peter H. Rolfs, s/n, Campus, DPE 36570-000 - Viçosa - MG e-mail: rosimar@ufv.br

\begin{abstract}
Considering the organization of the National Congress established since the 1988 Federal Constitution, the present work has as its purpose to investigate the role of the Legislative Power in the formulation of curriculum policies in Brazil, highlighting and discussing the agenda proposed within the sphere of that Power for the matters concerning this issue. To such end, all proposals about education presented and concluded in their legislative process during the 50th, 51st, and 52nd legislatures (1995-2007) were identified and, among these, those that took school curricula as their subject matter. In this way, the work analyzes the legislative process followed by 29 proposals about school curriculum, three of which eventually became legal norms. The conclusion was that the Legislative exerts little power to set the agenda for curriculum policies, limiting its proposals to the creation or modification of school disciplines. In the conception of curriculum policy expressed in the proposals presented it is as if the school curriculum was formed from the outside of the schools through the incongruous summation of disciplines supposedly relevant to minimize social flaws. The proposals do not seem to derive inspiration from the objectives germane to the school institution, but from the social problems themselves. They disregard the context of the practice, revealing procedures in which the text of the curriculum policy seems to make sense in itself, outside the processes of recontextualization and hybridism that are fundamental to understand curriculum policies as cultural policies.
\end{abstract}

\section{Keywords}

Educational policy - Curriculum policies - School disciplines Legislative Power - Educational legislation. 
O sistema político formalizado no Brasil a partir da Constituição Federal de 1988 garante ao Poder Executivo amplos meios institucionais capazes de definir a sua predominância sobre o Poder Legislativo. Esses meios facultam um leque significativo de possibilidades ao Executivo, dentre as quais se destacam o instituto da medida provisória, a centralização dos trabalhos legislativos no Colégio de Líderes, a influência sobre os relatores, o poder de veto, a exclusividade de propor matérias em áreas específicas e de solicitar unilateralmente urgência para matérias de sua autoria, além da patronagem, disponível por meio da negociação de cargos no interior da administração federal (Figueiredo; Limonge, 1998; 1999; Moraes, 2001; Pereira; Mueller, 2000; Rodrigues, 2002; Santos, 1997; Santos, 1998; 2002; 2003; Santos; Acir, 2005).

Esse conjunto de fatores corrobora para garantir ao Executivo inequívoco controle sobre a agenda legislativa brasileira, com predomínio sobre o total de leis sancionadas e alta proporção de aproveitamento em relação às proposições que inicia no Congresso Nacional. Já as proposições iniciadas pelos parlamentares revelam um percentual de aproveitamento muito aquém daquele apresentado pelo Executivo e não parecem usufruir da estrutura partidária como meio de organização. Os elementos que parecem influenciar o sucesso das proposições apresentadas pelos parlamentares se referem mais às suas características pessoais, tais como antiguidade na carreira legislativa, força eleitoral, posição ocupada na estrutura burocrática do Legislativo ou mesmo a experiência anterior no Executivo (Amorim Neto; Santos, 2002).

Considerando a organização do Congresso Nacional brasileiro instituída a partir da Constituição Federal de 1988, este trabalho tem o objetivo de investigar o papel do Poder Legislativo na formulação das políticas curriculares, destacando e discutindo a agenda proposta no âmbito desse Poder para as matérias sobre esse tema. Entendemos, conforme Pacheco (2003), que as políticas curriculares, em termos formais, correspondem ao conjunto de leis e regulamentos sobre o que deve ser ensinado nas escolas. Entretanto, as políticas curriculares não se limitam ao contexto formal, significam também uma ação simbólica, representando uma ideologia para a organização da autoridade e que abrange tanto as decisões das instâncias da administração central como as decisões dos contextos escolares. Assim, as políticas curriculares são, ao mesmo tempo, processo e produto, envolvendo tanto a produção de intenções, ou de textos, como a realização de práticas ou de ações concretas. Os textos curriculares oriundos da administração central simbolizam o discurso oficial do Estado e representam interesses diversos e alianças em variados níveis de ação.

Essa compreensão das políticas curriculares, produzidas em contextos interdependentes (Ball; Bowe, 1998) e simbólicos, reúne vários estudiosos sobre currículo no Brasil (Lopes, 2002; 2004; 2006a; 2006b; 2006c; Teixeira, 2008; Matos; Paiva, 2007; Paiva; Frangella; Dias, 2006; Dussel, 2002; Oliveira; Destro, 2005), os quais definem as políticas curriculares a partir dos processos de hibridação e de recontextualização que as constituem. Segundo Lopes (2004):

[...] ao circularem no corpo social da educação, os textos, oficiais e não oficiais são fragmentados, alguns fragmentos são mais valorizados em detrimento de outros e são associados a outros fragmentos de textos capazes de ressignificá-los e refocalizá-los. [...] Nessa rede, há uma crescente bricolagem de discursos e textos, acentuando o caráter híbrido das políticas culturais, dentre elas as políticas curriculares. Concepções as mais distintas são associadas nas políticas, perdendo sua relação com os discursos originais. (p. 112)

Afirmar que as políticas curriculares extrapolam a ação do Estado e dos governos, envolvendo diversos decisores na produção de textos a partir de uma cadeia cíclica e interdependente, contudo, não significa desconsiderar, conforme afirma Lopes (2004), o poder privilegiado que o Estado possui na produção dos sentidos das políticas. Por isso, sem negar o 
caráter complexo que constitui as políticas curriculares, esse artigo destacará o Poder Legislativo como ator significativo na formalização dessas políticas, com o objetivo de conhecer como é exercido o poder do Estado de definir a agenda federal para as políticas curriculares no Brasil por meio do processo legislativo. Isso não significa presumir, evidentemente, que as políticas curriculares estejam subsumidas na ação desse ator.

Para consecução do objetivo mencionado acima, foram identificadas todas as proposições sobre educação apresentadas e concluidas no processo legislativo durante as $50^{\mathrm{a}}, 5^{\mathrm{a}}$ e 52a legislaturas (1995-2007), analisando-se, entre estas, aquelas que tomam como objeto o currículo escolar, que foi tema de 34\% do total de proposições sobre educação encerradas no referido período. Destaca-se que todas as proposições sobre currículo escolar identificadas abordam a criação de disciplinas escolares ou a inclusão de critérios para o oferecimento destas pelas escolas. Mesmo sabendo que as políticas curriculares não se resumem às disciplinas escolares, optou-se por manter a terminologia políticas curriculares como orientação para análise do conteúdo dos documentos estudados (Bardin, 2008), o que evidenciou a concepção restritiva de currículo presente nas proposições apresentadas à Câmara dos Deputados durante o período analisado. Dessa maneira, o trabalho analisa o processo legislativo de 29 proposições sobre currículo escolar, 3 das quais transformadas em norma jurídica, alterando a Lei de Diretrizes e Bases da Educação Nacional de 1996 (LDB/96). A partir dessa análise, pretende-se discutir a agenda do Legislativo para as políticas curriculares, destacando não só o conteúdo dessa agenda, mas o efetivo poder exercido pelo Legislativo para influenciar e definir as políticas curriculares nacionais.

As fontes utilizadas para pesquisa foram os Diários da Câmara dos Deputados, do Senado Federal e do Congresso Nacional, nos quais são publicados os documentos que registram todo o processo legislativo, incluindo as propo- sições, os pareceres, os requerimentos, as discussões, as votações, os pronunciamentos e todos os demais procedimentos realizados pelo Congresso Nacional na íntegra.

\section{Proposições transformadas em norma jurídica}

No período analisado, foram apresentados e aprovados três Projetos de Lei - PLs -, propondo criar disciplina no currículo escolar ou acrescentar critérios àquelas existentes, conforme mostra o Quadro 1. O PL n. 2.757/97 foi, dentre eles, o mais célere, aprovado em regime de urgência no período de somente cinco meses. lsso se deveu a dois fatores determinantes: a natureza do tema a que se referiu, conforme análise a seguir, e o apoio do Poder Executivo.

A proposta do Deputado Nelson Marchezan (PSDB/RS) era modificar o artigo 33 da, na época, recém-promulgada $\mathrm{LDB} / 96$, que dispunha sobre a oferta da disciplina ensino religioso nas escolas de Ensino Fundamental: facultativa para os alunos e sem ônus para os cofres públicos. A modificação que seria introduzida no artigo era exatamente supressiva da expressão "sem ônus para os cofres públicos”. Polêmico, o artigo foi um dos mais fortes focos de discussão suscitados pela LDB/ 96, gerando forte pressão pela sua alteração, sobretudo pelos segmentos católicos. Direcionada tanto ao Congresso Nacional quanto ao Governo, essa pressão acabou resultando na proposição de três PLs sobre o assunto: um do Deputado Nelson Marchezan (PSDB/RS), outro do Poder Executivo e, ainda, um terceiro do Deputado Maurício Requião (PMDB/PR), esses dois últimos apensados àquele primeiro na Câmara dos Deputados e prejudicados pela sua aprovação. 0 fato de o projeto do Executivo ter tramitado apensado ao do Deputado Nelson Marchezan (PSDB/RS), entretanto, se bem que do mesmo partido do Governo Fernando Henrique Cardoso, é de ordem simplesmente cronológica e regimental, não de prioridade ou importância política, já que o apoio recebido, fundamental para a aprovação do projeto e em tão pouco 
QUADRO 1: Tramitação das proposições sobre currículo escolar transformadas em norma jurídica.

\begin{tabular}{|c|c|c|c|c|}
\hline \multirow{2}{*}{\multicolumn{2}{|c|}{ Tramitação }} & \multicolumn{3}{|c|}{ Projeto de Lei } \\
\hline & & \begin{tabular}{|l|}
$2.757 / 97$ \\
\end{tabular} & $2.758 / 97$ & $259 / 99$ \\
\hline \multicolumn{2}{|l|}{ Autor } & Nelson Marchezan & Pedro Wilsor & Esther Gross \\
\hline \multicolumn{2}{|l|}{ Partido } & PSDB/RS & $\mathrm{PT} / \mathrm{GO}$ & PT/RS \\
\hline \multirow{2}{*}{ Apreciação } & Câmara dos Deputados & Plenário & $\mathrm{ACC}^{*}$ & $\mathrm{ACC}^{*}$ \\
\hline & Senado Federal & Plenário & Plenário & Plenário \\
\hline \multirow{2}{*}{ Regime } & Câmara dos Deputados & Urgência & Ordinário & Ordinário \\
\hline & Senado Federal & Urgência & Ordinário & Ordinário \\
\hline \multirow{3}{*}{ Tempo em meses } & Câmara dos Deputados & 04 & 54 & 37 \\
\hline & Senado Federal & 01 & 04 & 09 \\
\hline & Total & 05 & 58 & 46 \\
\hline \multicolumn{2}{|r|}{ Lei } & $9.475 / 97$ & $10.328 / 01$ & $10.639 / 03$ \\
\hline
\end{tabular}

- Apreciação Conclusiva das Comissões.

Fonte: Diários da Câmara dos Deputados, do Senado Federal e do Congresso Nacional de 1997 a 2003.

tempo, teve forte influência tanto do Ministério da Educação - MEC - quanto da base governamental no Congresso.

Introduzido em regime de tramitação ordinário e, inicialmente, com apreciação conclusiva das comissões, o PL n. 2.757/97 foi objeto de requerimento de urgência, deferido pelo Plenário da Câmara dos Deputados, apoiado por ampla gama de partidos da base aliada, mas também de oposição ao Governo Fernando Henrique Cardoso, como foi o caso do Deputado Neiva Moreira (PDT/MA), líder do bloco PT, PDT e PCdoB. Garantida a urgência, o PL foi introduzido na Ordem do Dia para apreciação, discussão e votação. 0 Deputado Padre Roque (PT/PR) foi designado para emissão de parecer em substituição à Comissão de Educação, Cultura e Desporto - CECD - e o Deputado Nilson Gibson (PSB/PE), em substituição à Comissão de Constituição, Justiça e Redação - CCJR. Ambos proferiram parecer pela aprovação do $\mathrm{PL}$ n. 2.757/97, com substitutivo que integra elementos dos três projetos, destacadamente a supressão da mencionada expressão "sem ônus para os cofres públicos".

Os projetos suscitaram debates e, pronunciando-se favoravelmente ao substitutivo apresentado pelo Deputado Padre Roque (PT/ $\mathrm{PR}$ ), o Deputado Inocêncio Oliveira (PFL/PE) destaca seu papel no acordo prévio estabelecido entre as lideranças para aprovação do substitutivo citado. Ele diz:

[...] quando esta casa, em votação histórica, aprovou a $L D B$, Lei de Diretrizes e Bases da Educação Nacional, cometeu um equívoco ao excluir o ensino religioso. [...] Congratulo-me com o Deputado Padre Roque pelo substitutivo, e com as demais Lideranças, das quais fui um dos intermediários a fim de chegarmos a um entendimento que possibilitasse a votação desta matéria, cujo prazo constitucional está vencido. E a Câmara dos Deputados, cumprindo seu dever, haverá de votá-la, para que possamos ter no País o verdadeiro ensino religioso, que professe 0 amor à paz, à justiça, ao trabalho, aos direitos humanos, à cidadania, e sobretudo a crença em Deus. Acima de Deus, nada existe. E nada seríamos sem Ele, porque somos um grão de areia neste universo do qual Deus é o supremo criador. (Câmara dos Deputados: 1997a, 16.521, grifos meus)

0 Deputado Salvador Zimbaldi (PSDB/SP) também esclarece quanto ao esforço realizado, inclusive com a participação do MEC e de instituições civis religiosas, para a aprovação dos 
projetos. Afirma no seu pronunciamento pela aprovação do substitutivo que

[...] durante inúmeras reuniões, inclusive com a participação do Ministro da Educação, Paulo Renato [de Souza], e de representantes de várias religiões, como da CNBB [Conferência Nacional dos Bispos do Brasil] e da Associação Nacional dos Pastores, foi discutido esse projeto em busca de um consenso, para que pudesse ser submetido ao Plenário. (Câmara dos Deputados, 1997a, 16.523, grifos meus)

Desse modo, a introdução dos Pls na Ordem do Dia foi momento de formalizar um acordo já estabelecido pela aprovação do projeto. 0 substitutivo do Deputado Padre Roque (PT/ PR) ao PL n. 2.757/97 e apensados foi aprovado nesses termos, por votação simbólica, e encaminhado para revisão do Senado Federal, que deliberou sobre a matéria em menos de um mês, já que foi recebida em 23 de junho 1997 e sancionada em 22 de julho do mesmo ano.

No Senado Federal, o PL tramitou também em regime de urgência, tendo o Senador Joel de Hollanda (PFL/PE) proferido pareceres pelas Comissão de Educação - CE - e Comissão de Constituição e Justiça - CCJ -, ambos pela aprovação e contrários à emenda de Plenário apresentada pelo Senador Abdias Nascimento (PDT/RJ). Essa rejeição, segundo o Senador Sebastião Rocha (PDT/AP), ocorreu mais pela preocupação com a urgência na aprovação do projeto do que propriamente em função do seu conteúdo. Nas suas palavras, "o Relator ofereceu parecer contrário, rejeitando-a em função da possibilidade de atrasar a aprovação da Lei no Congresso e sua consequente implementação". (Senado Federal, 1997, 13.454).

0 projeto foi amplamente debatido no Plenário do Senado Federal sob a audiência atenta de representantes dos cultos afro-brasileiros, da igreja católica e das igrejas evangélicas, como menciona o Senador Roberto Requião (PMDB/PR). A preocupação durante o debate com essas presenças é referência constante nas intervenções. A Senadora Emília Fernandes (PTB/ RS) também faz esse destaque ao acrescentar no seu discurso: "lembro que há pessoas de várias religiões aqui neste momento". Entretanto, o longo debate não parece ter significado efetiva disputa política entre propostas distintas sobre a matéria em tramitação, sobre a qual, aliás, foi apresentada uma única emenda. É esse o entendimento, por exemplo, da Senadora Benedita da Silva (PT/RJ) que, discutindo aspectos do projeto relativos à liberdade religiosa, admite não ser esse o verdadeiro foco do debate, "pois se trata de uma matéria vencida, garantida" (Senado Federal, 1997, 13.455; 13.457).

Encerrada a discussão sem maiores polêmicas, o projeto foi aprovado também no Senado Federal pelo processo de votação simbólico, tendo sido encaminhado para sanção e transformado na Lei n. 9.475/97, a primeira modificação sofrida pela LDB/96 com apenas sete meses de vigência. Outras propostas de modificação surgiram também logo nos primeiros meses seguintes à sua promulgação, como foi o caso do PL n. 2.758/97, do Deputado Pedro Wilson (PT/GO), apresentado em fevereiro de 1997. Entretanto, a tramitação desse PL foi muito mais demorada que a do anterior não cinco meses, mas quase cinco anos.

0 PL n ${ }^{\circ} 2.758 / 97$ propunha introduzir o termo "obrigatório" no parágrafo da LDB/96 que dispõe sobre a oferta da disciplina educação física nos currículos do Ensino Fundamental e Médio, garantindo a obrigatoriedade não explicitada na redação original da Lei. Tendo sido submetido ao regime de tramitação ordinário e à apreciação conclusiva das comissões, não foi objeto de nenhuma emenda nem voto separado na CECD, no qual o Relator Pedro Yves (PPB/SP) emitiu breve parecer justificando seu voto pela aprovação em virtude do fato de que

[...] a proposição não altera o espírito do dispositivo cuja redação pretende modificar [LDB/96]. Ao contrário, reforça a intenção do legislador em fazer constar obrigatoriamente a educação física como componente 
curricular da educação básica. (Câmara dos Deputados, 2001a, 26.346)

$\mathrm{Na}$ CCJR, entretanto, o PL permaneceu durante quatro anos, tendo passado pelas mãos de quatro relatores. 0 primeiro, Deputado Magno Bacelar (PFL/MA), chegou a emitir parecer favorável ao Projeto, mas que não chegou a ser votado pela Comissão até o arquivamento do PL no final da $50^{\circ}$ legislatura. Desarquivado a pedido do autor no início da legislatura seguinte e reencaminhado pela Mesa à CCJR, recebeu novamente parecer favorável do segundo Relator, Deputado Ciro Nogueira (PFL/PI), mas também dessa vez não logrou ser votado em função da saída do Deputado dessa Comissão. 0 terceiro Relator, Deputado Gerson Peres (PPR/PA), por sua vez, nem chegou a emitir parecer antes da sua retirada da CCJR. Finalmente, por meio do parecer do Relator Moroni Torgan (PFL/CE) é que o PL n. 2.758/97 foi votado e aprovado na CCJR, por unanimidade.

Encaminhado ao Senado Federal, o PL foi aprovado em menos de quatro meses, nos mesmos termos do substitutivo da CCJR na Câmara dos Deputados. 0 Senador Moreira Mendes (PFL/ RO), a quem coube a relatoria do Projeto na CE, concluiu seu trabalho em apenas dezessete dias, praticamente repetindo em seu parecer os termos daquele apresentado pela CECD da Câmara dos Deputados. Concorda que "o legislador não tinha intenção de tornar a Educação Física disciplina de oferta optativa”, e que "a proposição não altera o espírito do dispositivo cuja redação pretende modificar". O Projeto não recebeu emendas e nenhuma inscrição para discussão em Plenário, tendo sido aprovado, encaminhado à sanção e transformado na Lei n. 10.328/01' (Senado Federal, 2001, 24.602-03).

Quanto ao PL n. 259/99 - sancionado com vetos no final da $51^{\text {a }}$ legislatura, já no começo do Governo Luis Inácio Lula da Silva este tem a contraditória autoria da Deputada Esther Grossi (PT/RS) e coautoria do Deputado Ben-Hur Ferreira (PT/MS). Contraditória porque, se em outras oportunidades, como relatora de vários projetos na CECD propondo introdução de disciplinas no currículo, a Deputada alega os obstáculos da legislação vigente às iniciativas com esse conteúdo, rejeitando-as por sua inadequação. Agora, o seu PL dispõe exatamente "sobre a obrigatoriedade da inclusão, no currículo oficial da rede de ensino, da temática "história afro-brasileira' e dá outras providências". 0 Projeto define o conteúdo programático a ser ministrado, que deverá ocupar 10\% da programação das disciplinas História do Brasil e Arte no Ensino Médio, "incluindo o estudo da História da África e dos africanos, a luta dos negros no Brasil, a cultura negra brasileira e o negro na formação da sociedade nacional, resgatando a contribuição do povo negro nas áreas social, econômica e política”. E ainda estabelece que os cursos de capacitação de professores deverão contar com a participação de entidades do movimento afro-brasileiro e outras instituições de ensino e pesquisa envolvidas com essa matéria (Câmara dos Deputados, 1999b, 36.738).

Na CECD, a aprovação do PL, com apreciação conclusiva, também merece destaque, já que contraria não só a recorrência de inúmeros pareceres anteriores, rejeitando proposições dessa natureza, mas inclusive a Súmula $n^{\circ} 01 /$ 01 da própria CECD, que recomenda o encaminhamento de propostas desse tipo sob a forma de indicação, não de PL (Câmara dos Deputados, 2001c).

0 Relator na CECD, Deputado Evandro Milhomem (PSB/AP), justifica seu voto favorável em virtude de critérios eminentemente políticos, alegando a importância do Projeto para o resgate da cidadania dos negros, já que, segundo ele,

[...] passados mais de cem anos depois da abolição da escravatura no País, a triste conclusão que se extrai é a de que os negros ainda não foram integrados na vida social, política e cultural da sociedade brasileira. (Câmara dos Deputados, 1999a, 36.740)

1. Atualmente, essa norma está revogada pela Lei $n^{\circ} 10.793 / 03$, que inclui critérios para a fruição do caráter facultativo da disciplina pelo aluno. 
Recebendo o PL para revisão, o Senado Federal concluiu sua tarefa em nove meses, aprovando-o e encaminhando-o para sanção. Não houve discussão nem acréscimos ou modificações no PL por meio do parecer do Relator Geraldo Cândido (PT/RJ), tendo sido adiada a primeira votação por falta de quorum. Foram introduzidas apenas modificações de redação, a pedido do Presidente do Senado Federal ao Relator, para adequá-lo ao texto da LDB/96. Remetido à Presidência da República, o PL foi sancionado com veto parcial, mantido pelo Congresso Nacional por falta de quorum nas reuniões deliberativas, inclusive da Comissão Mista encarregada de relatar o veto, que não apresentou relatório em tempo hábil.

Assim, a Lei $n^{\circ}$ 10.639/03 foi promulgada com dois vetos. 0 primeiro ao dispositivo que estabelece que as disciplinas História do Brasil e Arte, no Ensino Médio, deverão dedicar, pelo menos, dez por cento de seu conteúdo programático à história e cultura afro-brasileira. Referindo-se à $\mathrm{CF} / 88$ e à $\mathrm{LDB} / 96$, o Executivo justifica esse veto argumentando que o parágrafo "não atende ao interesse público consubstanciado na exigência de se observar, na fixação dos currículos mínimos de base nacional, os valores sociais e culturais das diversas regiões e localidades de nosso país". 0 segundo veto refere-se ao artigo que dispõe sobre a participação de entidades do movimento afro-brasileiro, universidades e outras instituições de pesquisa relacionadas à história e cultura afro-brasileira nos cursos de capacitação para professores. A mensagem de veto alega inobservância do conteúdo da LDB/96, que não trata desses cursos de capacitação de professores. A sanção do artigo romperia, portanto, com a unidade dessa Lei, introduzindo norma estranha ao seu objeto (Congresso Nacional, 2003, p. 449).

\section{Proposições rejeitadas}

As proposições sugerindo introdução de disciplinas as mais diversas no currículo dos diferentes níveis de ensino somam 26 proposi- ções rejeitadas no período analisado. As disciplinas e os conteúdos sugeridos são variados: ensino das religiões, educação no trânsito, noções de trânsito, educação em saúde para a cidadania, educação e segurança alimentar, linguagem de programação de computador, computação, informática, estudo da Constituição Federal, direitos básicos do cidadão, noções de direito, educação tributária, normas gerais de orçamento e finanças públicas, educação física obrigatória para o ensino superior, latim, introdução à comunicação de massa, educação no campo para os cursos de formação de professores, ensino profissionalizante obrigatório no ensino médio, segurança pública. Se essas proposições tivessem sido convertidas todas em lei, como afirma em parecer o Deputado Gastão Vieira (PMDB/MA),

[...] nossas crianças estariam estudando umas trinta ou mais disciplinas, além das [...] que já são previstas na lei que rege a educação escolar, como português, matemática, ciências, educação artística etc. (Câmara dos Deputados, 2002, p. 2)

Nas justificativas que acompanham as proposições dessa natureza, argumenta-se como se a educação escolar fosse capaz de sanar mazelas sociais que variam desde a violência até o esvaziamento do campo em favor das cidades. A escola é percebida como a instituição capaz de promover a redenção de uma sociedade em crise. 0 meio sugerido para isso é a criação de disciplinas que, em alguns casos, voltam-se fundamentalmente para um conteúdo moral, buscando a formação de valores que, na avaliação dos autores dessas proposições, encontrar-se-iam ausentes na sociedade. É assim, por exemplo, que o Deputado José Carlos Coutinho (PFL/RJ) entende que o ensino obrigatório de "noções de direito", a partir da $5^{\text {a }}$ série do ensino fundamental, corroboraria para a eliminação de comportamentos sociais violentos, já que

\section{[...] a educação é o maior fator de promoção} da ordem no seio da sociedade. [...] A falta 
de educação é o que, realmente, determina a formação destas gangues de rua que agora se multiplicam geometricamente, principalmente nas grandes cidades. (Câmara dos Deputados, 2000d, 60.064, grifos meus)

Em sentido análogo, o Deputado Ildemar Kussler (PSDB/RO) entende que a inclusão da disciplina "educação no trânsito" nos currículos escolares do ensino fundamental resolveria a violência e a desordem presentes no trânsito, uma vez que esses problemas decorreriam, basicamente,

[...] da falta de educação para o desenvolvimento de comportamentos coletivos e responsáveis e de atitudes de respeito pela vida. Essa educação só será eficaz se for dada de maneira compulsória e sistemática, pela formação de bons hábitos, como as escolas estão acostumadas a fazer. (Câmara dos Deputados, 1995, 23.330, grifos meus)

A obrigatoriedade da "educação física", inclusive nos cursos superiores, também tem, segundo o Deputado Alberto Fraga (PMDB/F), um importante papel social a cumprir além de fomentadora do espírito esportivo, fazendo da escola um elemento-chave para a formação de novos atletas. Segundo ele,

[...] são inúmeras as vantagens, quer no plano da convivência humana, com diminuição da criminalidade, por exemplo, quer no campo da saúde pública. (Câmara dos Deputados, 2000c, 53.155, grifos meus)

0 descuido com o meio ambiente é outro problema social em relação ao qual o currículo escolar tem importante função reparadora, conforme o Deputado José Carlos Coutinho (PFL/J). Segundo ele, é preciso uma mudança de atitude que só a introdução do conteúdo de "educação ambiental" no currículo de todos os níveis de escolaridade pode realizar. Também é a escola responsável, na perspectiva do Deputado Inácio Arruda (PCdoB/CE), "pela formação de uma nova consciência sanitária, resultante da compreensão dos determinantes sociais, econômicos e políticos do processo saúde-doença”, viabilizada pela introdução da disciplina "educação em saúde para a cidadania" nos currículos do ensino fundamental e do ensino médio (Câmara dos Deputados, 1997b, 40.615).

0 Senador Geraldo Cândido (PT/J), preocupa-se com o modo como os chamados veículos de comunicação de massa exercem sua função educadora, "sem um quadro explícito de responsabilidade social”. A inclusão, então, da disciplina "introdução à comunicação de massa”, como tópico curricular no ensino médio, teria como objetivo central "dar uma visão geral ao estudante do funcionamento destes veículos" (Senado Federal, 1999, 19.364-65, grifos meus).

Para o Deputado Adão Preto (PT/RS), aquilo que chamou de "cultura urbanóide" é uma das principais causas que levou a que "mais de dois milhões de pessoas abandonassem o campo e se transferissem para a cidade". Trata-se da supervalorização da orientação urbana que ocorre nas escolas localizadas no campo, comportamento que precisa ser revertido por meio do "resgate da introdução de conteúdos relativos a estas questões [do campo] no currículo da formação dos educadores" (Câmara dos Deputados, 2001b, 6.623).

Assim, na concepção expressa por meio dessas proposições, é como se o currículo escolar se compusesse, de fora para dentro das escolas, pelo somatório de disciplinas sem necessária conexão entre si, mas pretensamente importantes para o bom funcionamento da sociedade. Não são preocupações de tais projetos os objetivos precípuos da instituição escolar, mas as próprias problemáticas sociais que os inspiraram. Os projetos analisados desconsideram o contexto da prática, revelando procedimentos para os quais o texto da política curricular parece fazer sentido em si mesmo, fora dos processos de recontextualização e hibridismo fundamentais para o entendimento das políticas curriculares como políticas culturais (Lopes, 2002; 2004; 2005; 
2006a; Teixeira, 2008; Oliveira; Destro, 2005). Somente nessa condição é que tais políticas curriculares poderiam alcançar o status de "orientar determinados desenvolvimentos simbólicos, obter consenso para uma dada ordem e/ou para uma transformação social almejada”, conforme pretendem as proposições para a criação de disciplinas escolares apresentadas pelos parlamentares (Lopes, 2004, p. 113).

Além disso, não parece, também, preocupação dos autores desses projetos a institucionalização da norma propriamente, mas principalmente a sua proposição como fim último. lsso pode ser percebido, inclusive, pela iniciativa de proposição de Pls que praticamente repetem o conteúdo de outro já em tramitação. Existem casos de proposições de mesmo conteúdo apresentadas pelo mesmo autor como o PL no 3.779/00 e o PL no 5.543/01, de autoria do Deputado José Carlos Coutinho (PFL/RJ) ambos propondo criar disciplina sobre noções de direito -, bem como o PL no 825/99 e o PL $\mathrm{n}^{\circ} 5.692 / 01$, de autoria do Deputado Glycon Terra Pinto (PMDB/MG) - ambos propondo inclusão obrigatória da disciplina linguagem de programação de computador nos currículos de ensino médio. Nessas circunstâncias, ou para pequenas modificações e acréscimos de questões pontuais sobre conteúdo já em tramitação, o tipo de proposição mais adequado, segundo o regimento da própria Câmara dos Deputados, não parece ser outro senão uma emenda. No entanto, certamente, não têm a visibilidade que alcançam, no processo legislativo, os PLs. Estes figuram inclusive como critério que agrega mérito ao currículo dos parlamentares, já que a quantidade de projetos apresentados parece atribuir caráter de eficiência aos seus autores, valor importante à carreira política.

A insistência na proposição de projetos para criação de disciplinas escolares ocorre, além de tudo, à revelia da própria orientação interna da Câmara dos Deputados, por meio de nota técnica emitida pela consultoria legislativa da área de educação, cultura, desporto, ciência e tecnologia. Segundo a nota técnica, proposi- ções sobre currículo não devem sequer constituir-se objeto de projeto de lei ou de emenda, mas de indicação ou de discurso parlamentar, já que legislar sobre essa matéria extrapola a competência do Poder Legislativo, invadindo consequentemente a do Poder Executivo (Almeida Jr., 2003). Entretanto, em outras oportunidades, contraditoriamente, a própria CECD aprova projetos com esse conteúdo, conforme demonstra a sessão anterior.

A maioria dos pareceres proferidos pela CECD é uníssona no reconhecimento da impertinência desses Pls introduzindo disciplinas no currículo das escolas. Em seu voto pela rejeição dos Pls nº 825/99 e 2.585/00, o Relator João Matos (PMDB/SC) escreve que "do ponto de vista estritamente legal, todos sabemos que a definição de disciplinas no currículo escolar do ensino fundamental e médio é da competência do Ministério da Educação - MEC, ouvido o ConseIho Nacional de Educação" (Câmara dos Deputados, 2000a, 24.021, grifos meus). Entretanto, nem as afirmações repetidas desse teor, incluídas na quase totalidade dos pareceres que analisam os PLs propondo criação de disciplinas escolares, foram capazes de inibir tais iniciativas, que parecem ter sido erigidas, além de tudo, na insularidade burocrática do Poder Legislativo, num diálogo surdo com o que Lopes (2006b; 2006c) definiu como comunidades epistêmicas, que são formadas por grupos que compartilham concepções, valores e regimes de verdade comuns entre si e que atuam nas políticas em função da posição que ocupam em relação ao conhecimento, pois constituem uma rede de profissionais com competência reconhecida em um domínio particular que produz legitimidade social para influenciar nas políticas em nível local, nacional ou global. Não obstante o fato de as comunidades epistêmicas exercerem grande influência sobre as políticas curriculares nacionais, suas ações em relação à produção do texto curricular, particularmente no que se refere à disciplinarização do currículo, são direcionadas para as instâncias políticas legitimadas pelo arcabouço normativo vigente - no caso dos Parâmetros e Diretrizes Curriculares Nacionais 
- PCN -, o MEC e o CNE². 0 Congresso Nacional, assim, exerce uma função regulatória atípica para a definição da matriz curricular das escolas, constituindo-se num canal paralelo com o qual dialogam apenas tangencial e indiretamente as comunidades epistêmicas.

Esse diálogo tangencial e indireto ocorre mediante os pareceres aprovados na CECD sobre a criação de disciplinas escolares, que registram uma satisfação dessa Comissão com as normas e o conteúdo que definem atualmente os currículos das escolas. Ratificam, por um lado, o arcabouço jurídico que define as competências do MEC para a elaboração das diretrizes curriculares nacionais, conforme já demonstrado acima, e exaltam, por outro lado, o caráter interdisciplinar que tornaria os PCN completos na sua abrangência. Os argumentos do Relator Pedro Wilson (PT/GO), contrários à criação da disciplina "normas gerais de orçamento e finanças públicas”, por exemplo, ressaltam a interdisciplinaridade e a contextualização que, presentes nos Parâmetros Curriculares Nacionais, dispensariam a inclusão dessa disciplina proposta no PL no 1.996/99. Recentemente, afirma ele,

\section{[...] o MEC elaborou os Parâmetros Cur-} riculares Nacionais (PCN); [...] entendemos, como educadores engajados na problemática curricular, que a temática 'orçamento e finanças públicas' deva ser tratada de forma interdisciplinar e contextualizada, permeando as diferentes disciplinas do currículo já existentes. (Câmara dos Deputados, 2000b, 25.554, grifos meus)

A Relatora Esther Grossi (PT/RS), em seu parecer ao $\mathrm{PL} \mathrm{n}^{\circ}$ 3.728/00, que propõe incluir "educação ambiental" nos currículos do ensino fundamental, médio e superior, concorda com os argumentos acima e finaliza ${ }^{3}$ :

[...] entendemos, assim, não ser competência da Câmara [de Educação, Cultura e Desporto] a inclusão de conteúdos mínimos, e observamos que a aspiração de ter meio ambiente como conteúdo se encontra pre- visto nos documentos normativos em vigor.

(Câmara dos Deputados 2001c, p. 2)

Os pareceres aprovados pela CECD, desse modo, não poupam argumentos que ressaltam a pertinência da política curricular em vigor, restando à avaliação, como destacado no parecer acima da Relatora Esther Grossi (PT/RS), de que o alcance dos padrões universais de qualidade no processo de ensino-aprendizagem depende somente da efetiva implementação dessa política.

A CECD cumpre o papel de preservar as normas anteriormente instituídas pelo próprio Congresso Nacional, que definiram, por exemplo, as competências para elaboração das políticas curriculares nacionais. Por outro lado, adere à natureza dessas políticas, uma vez que ressalta como pertinentes e abrangentes o seu conteúdo ${ }^{4}$. Exerce, desse modo, um papel conservador em relação às proposições que sugerem introduzir disciplinas no currículo, rejeitando tais matérias e, consequentemente, mantendo o status quo. Com isso, preservam a organização escolar da introdução de normas curriculares que não acrescentariam mérito ao arcabouço institucional vigente e, conforme se argumentou, trazem concepções equivocadas quanto aos objetivos intrínsecos da instituição escolar, cumprindo mais o objetivo de avolumar as estatísticas de proposições per capita apresentadas por parlamentar.

\section{Considerações finais}

Destaque nas proposições sobre currículo escolar transformadas em norma jurídica, todas com a finalidade de introduzir modificações na

2. Sobre a relação entre o MEC e o CNE na elaboração das diretrizes e parâmetros curriculares nacionais para o ensino fundamental, por exemplo, Bonamino e Martinez (2002) destacam o fato de que o MEC privilegiou interlocutores e referenciais externos na sua elaboração curricular, gerando resistência no âmbito do CNE e também nos espaços acadêmicos e escolares. 3. A própria Deputada, entretanto, apresentou em outra oportunidade o PL $n^{0}$ 259/99, transformado na Lei n 10.639/03, propondo a introdução no currículo escolar do conteúdo história afro-brasileira.

4. Alternativamente a essa concepção, abordagens críticas sobre currículos nacionais, sobretudo quanto aos Parâmetros Curriculares Nacionais em vigor, foram formuladas em Moreira (1996), Silva (1995), Silva e Gentili (1996). 
LDB/96, é a discrepância entre o processo de tramitação daquelas apresentadas pelos deputados e aquela que tramitou em conjunto com proposta do Executivo. Se as primeiras foram aprovadas em regime ordinário no tempo médio de mais de quatro anos, a última foi concluída em regime de urgência em apenas cinco meses. A análise da tramitação desses projetos revela a grande diferença de tratamento legislativo que recebem os projetos originados no próprio Legislativo e aqueles originados no Executivo. Há evidente privilégio desses últimos em detrimento dos primeiros. Quando há influência, direta ou indireta, do Executivo, a arena de decisão legislativa se desloca do Congresso Nacional, desqualificando, por exemplo, as comissões, e se institui nos espaços da administração federal controlados pelo Poder Executivo. As matérias, assim, chegam resolvidas no Congresso apenas para formalização. Já as matérias originadas no próprio Legislativo, de autoria de deputados, senadores ou comissões, submetem-se a todo rigor ritual do processo definido regimentalmente, inclusive com atuação e influência evidente das comissões. Há discussão e debate sobre o mérito dos projetos em relação a que sua relevância como instituidor de norma passa a ser avaliado. É desse processo que o Executivo vê-se dispensado, na medida em que os seus projetos se submetem a outros meios de negociação.

Em decorrência desses fatores, os projetos originados no Legislativo, quando aprovados, têm tramitação muito mais lenta. Considerando, inclusive, que a própria disputa porventura existente entre partidos e/ou parlamentares acaba envolvida na disposição desses últimos para encaminhar, aprovando ou não, os projetos dos seus pares. Além do que, abordam temas pontuais, introduzindo minúcias no arcabouço normativo vigente, como é o caso das proposições aprovadas sobre currículo escolar.
As proposições sobre currículo escolar rejeitadas, por sua vez, indicam exemplos de dispersão e descuido dos parlamentares quanto às matérias sobre educação. São apresentados projetos de inclusão de disciplinas sobre temáticas sociais as mais variadas, sem qualquer preocupação com a natureza da matriz curricular que pretendem introduzir nas escolas. Se essas proposições fossem aprovadas, produziriam certamente uma realidade caótica nestas. lsso porque seus autores percebem as escolas distanciadas do que lhes constitui como instituições educativas, atribuindo-lhes função de remediadora e reparadora dos problemas emanados da estrutura complexa, capitalista e culturalmente heterogênea da sociedade.

Não há, entretanto, dispêndio de qualquer esforço legislativo de seus propositores para aprovação dessas matérias. São simplesmente rejeitadas pelas comissões por meio de pareceres que, no prazo regimental para interposição de recurso, não sofreram qualquer questionamento por parte dos autores e demais parlamentares. Parecem, conforme já mencionado, casos explícitos de projetos apresentados para avolumar a pauta legislativa e acrescentar a média per capita de projetos apresentados configurando-se nos chamados projetos estatísticos. Poder-se-ia concluir, a partir do estudo dessas proposições, que sua rejeição indica fraco poder de agenda do Legislativo para fazer aprovar matérias sobre educação. Entretanto, não parece oportuno fazê-lo, em virtude da evidência de que tais proposições nem chegam a se constituir como uma efetiva agenda legislativa para as políticas educacionais. São, antes, com raras exceções, uma "antiagenda", que desorganiza a educação em vez de organizá-la. Não evidenciam um plano, mas anunciam um caos legislativo contra o qual se previnem as comissões de mérito. 


\section{Referências bibliográficas}

ALMEIDA Jr., J. M. G. de. Proposições sobre currículo escolar em qualquer modalidade educacional ou nível de ensino. Nota técnica. Brasília: Consultoria Legislativa/Câmara dos Deputados, jun. 2003.

AMORIM NETO, 0.; SANTOS, F. A produção legislativa do Congresso: entre a paróquia e a nação. In: VIANNA, L. W. (Org.). A democracia e os três poderes no Brasil. Belo Horizonte: UFMG; Rio de Janeiro: IUPERJ; FAPERJ, 2002.

BALL, S. J.; BOWE, R. El curriculum nacional y su "puesta en práctica": el papel de los departamentos de materias o asignaturas. Revista de Estudios del Currículum, v. 1, n. 2, p. 105-131, 1998.

BARDIN, L. Análise de conteúdo. Lisboa: Edições 70, 2008.

BONAMINO, A.; MANTíNEZ, S. A. Diretrizes e parâmetros curriculares nacionais para o ensino fundamental: a participação das instâncias políticas do Estado. Educação e Sociedade. Campinas: CEDES, v. 23, n. 80, p. 368-385, set. 2002.

CÂMARA DOS DEPUTADOS. Ata da 96ª Sessão da Câmara dos Deputados, em 17 de junho de 1997. Diário da Câmara dos Deputados. Brasília: Câmara dos Deputados, p. 16.516-24, 17 jun. 1997a.

Ata da $97^{a}$ Sessão da Câmara dos Deputados, em 31 de maio de 2001. Diário da Câmara dos Deputados. Brasília: Câmara dos Deputados, p. 26.345-48, 01 jun. 2001 .

Parecer da Comissão de Educação, Cultura e Desporto ao Projeto de Lei no 259, de 1999. Diário da Câmara dos Deputados. Brasília: Câmara dos Deputados, p. 36.739-41, 25 ago. 1999a.

Parecer da Comissão de Educação, Cultura e Desporto ao Projeto de Lei ño 825, de 1999. Diário da Câmara dos Deputados. Brasília: Câmara dos Deputados, p. 24.020-023, 11 mai. 2000a.

Parecer da Comissão de Educação, Cultura e Desporto ao Projeto de Lei ñ 1.996, de 1999. Diário da Câmara dos Deputados. Brasília: Câmara dos Deputados, p. 25.553-55, 18 mai. 2000b.

Parecer da Comissão de Educação, Cultura e Desporto ao Projeto de Lei nº 5.529, de 2001. Brasília: Câmara dos Deputados, 11 out. 2002.

Projeto de Lei no 259, de 1999. Diário da Câmara dos Deputados. Brasília: Câmara dos Deputados, p. 36.738-39, 25 ago. 1999b.

Projeto de Lei no 3.680, de 2000. Diário da Câmara dos Deputados. Brasília: Câmara dos Deputados, p. 53.155, 27 out. 2000c.

Projeto de Lei n 3.779, de 2000. Diário da Câmara dos Deputados. Brasília: Câmara dos Deputados, p. 60.064, 24 nov. 2000d.

Projeto de Lei no 3.783, de 1997. Diário da Câmara dos Deputados. Brasília: Câmara dos Deputados, p. 40.615, 10 set. 1997b.

. Projeto de Lei nº 4.337, de 2001. Diário da Câmara dos Deputados. Brasília: Câmara dos Deputados, p. 6.623, 23 mar. $2001 b$.

Projeto de Lei no 933, de 1995. Diário da Câmara dos Deputados. Brasília: Câmara dos Deputados, p. 23.330, 23 set. 1995.

Súmula de recomendação aos relatores nº 01/2001, da Comissão de Educação, Cultura e Desporto. Brasília: Comissão de Educação, Cultura e Desporto, 12 set. 2001c.

CONGRESSO NACIONAL. Mensagem $n^{\circ}$ 06/2003-CN; $n^{\circ} 07 / 2003$, na Origem. Veto parcial $n^{\circ} 4$, de 2003, aposto ao Projeto de Lei da Câmara nº 17, de 2002. Diário do Congresso Nacional - Sessão Conjunta. Brasília: Congresso Nacional, p. 449-454, 15 mai. 2003. 
DUSSEL, I. 0 currículo híbrido: domesticação ou pluralização das diferenças? In: LOPES, A. C.; MACEDO, E. (Orgs.). Currículo: debates contemporâneos. São Paulo: Cortez, p. 55-77, 2002.

FIGUEIREDO, A.; LIMONGE, F. Executivo e Legislativo na nova ordem constitucional. Rio de Janeiro: FGV, 1999.

Relação Executivo-Legislativo no presidencialismo multipartidário: os regimes de 46 e 88. Caxambu: ANPOCS, 1998 (mimeo).

LOPES, A. C. Os parâmetros curriculares nacionais para o ensino médio e a submissão ao mundo produtivo: 0 caso do conceito de contextualização. Educação e Sociedade. Campinas: CEDES, v. 23, n. 80, p. 386-400, set. 2002.

Políticas curriculares: continuidade ou mudança de rumos? Revista Brasileira de Educação. Campinas: Autores Associados; ANPEd, 2004, n. 26, mai./ago., p. 109-183, 2004.

Política de currículo: recontextualização e hibridismo. Currículo sem fronteiras. Rio de Janeiro: PUC, v. 5, n. 2, p. 50-64, jul./dez. 2005.

. Integração e disciplinas nas políticas de currículo. In: LOPES, A. C.; MACEDO, E. F.; ALVES, M. P. C. (Orgs.). Cultura e política de currículo. Araraquara: Junqueira \& Marin, 2006a. p. 139-160.

Quem defende os PCN para o ensino médio? In: LOPES, A. C.; MACEDO, E. Políticas de currículo em múltiplos contextos. São Paulo: Cortez, 2006b. p. 126-158.

Discursos nas políticas de currículo. Currículo sem fronteiras. Rio de Janeiro: PUC, v. 6, n. 2, Jul./Dez., 33-52, 2006c.

MATOS, M. do C. de; PAIVA, E. V. de. Hibridismo e currículo: ambivalências e possibilidades. Currículo sem fronteiras. Rio de Janeiro: PUC, v. 7, n. 2, p. 185-201, jul./dez. 2007.

MORAES, F. Executivo e Legislativo no Brasil pós-constituinte. São Paulo em Perspectiva. São Paulo: Fundação Seade, v. 15, n. 4, p. 45-52, 2001.

MOREIRA, A. F. B. Os Parâmetros Curriculares Nacionais em questão. Educação \& Realidade. Porto Alegre: UFRGS, v. 21 n. 1 , p. 9-23, 1996.

OLIVEIRA, O. V. de; DESTRO, D. de S. Política curricular como política culturas: uma abordagem metodológica de pesquisa. Revista Brasileira de Educação. Campinas: Autores Associados; ANPEd, n. 28, p. 140-151, jan./abr. 2005.

PACHECO, J. A. Políticas curriculares: referenciais para análise. Porto Alegre: Artmed, 2003.

PAIVA, E.; FRANGELLA, R. de C. P.; DIAS, R. E. Políticas curriculares no foco das investigações. In: LOPES, A. C.; MACEDO, E. (Orgs.). Políticas de currículo em múltiplos contextos. São Paulo: Cortez, 2006. p. 241-269.

PEREIRA, C.; MUELLER, B. Uma teoria da preponderância do Poder Executivo: 0 sistema de comissões no Legislativo brasileiro. Revista Brasileira de Ciências Sociais. São Paulo: ANPOCS, v. 15, n. 43, p. 45-67, fev. 2000.

RODRIGUES, M. M. A. Accountability \& poder constitucional do Executivo brasileiro: decreto, medida provisória e tramitação de urgência. Teoria e Sociedade. Belo Horizonte: UFMG, n. 9, p. 158-201, jun. 2002.

SANTOS, F. Novas e velhas verdades sobre organização legislativa e as democracias. Dados - Revista de Ciências Sociais. Rio de Janeiro: IUPERJ, v. 41, n. 4, 1998.

0 Poder Legislativo no presidencialismo de coalizão. Belo Horizonte: UFMG; Rio de Janeiro: IUPERJ, 251 p., 2003.

Partidos e Comissões no presidencialismo de coalizão. Dados - Revista de Ciências Sociais. Rio de Janeiro: IUPERJ, v. 45, n. 2, p. 219-236, 2002.

SANTOS, F; ACIR, A. Teoria informacional e a seleção de relatores na Câmara dos Deputados. Dados - Revista de Ciências Sociais. Rio de Janeiro: IUPERJ, v. 48, n. 4, 2005. 
SANTOS, M. H. de C. Governabilidade, governança e democracia: criação de capacidade governativa e relações Executivo-Legislativo no Brasil Pós-Constituinte. Dados - Revista de Ciências Sociais. Rio de Janeiro: IUPERJ, v. 40, n. 3, 1997.

SENADO FEDERAL. Ata da $160^{a}$ Sessão Deliberativa Extraordinária, em 22 de novembro de 2001. Diário do Senado Federal. Brasília: Senado Federal, p. 24.602-03, 23 nov. 2001.

. Ata da 6a Sessão Deliberativa Ordinária, em 08 de julho de 1997. Diário do Senado Federal. Brasilia: Senado Federal, p. 13.449-61, 09 jul. 1997.

Projeto de Lei no 2.293, de 2000. Diário do Senado Federal. Brasília: Senado Federal, p. 19.364-5, 05 ago. 1999.

SILVA, T. T. da (Org.). Neoliberalismo, qualidade total e educação. Petrópolis: Vozes, 1995.

SILVA, T. T.da; GENTILI, P. (Orgs.). Escola S.A. Brasília: CNTE, 1996.

TEIXEIRA, B. de B. Uma política e vários contextos: os PCN do ensino fundamental. Revista Inter Science Place, ano 1, n. 3, p. 1-21, dez. 2008.

Recebido em 19.09.07

Aprovado em 27.05.09

Rosimar de Fátima Oliveira, doutora em Educação pela Universidade de São Paulo e professora do Programa de PósGraduação em Educação da Universidade Federal de Viçosa, onde coordena a Área de Fundamentos da Educação, é editora adjunto da Revista de Ciências Humanas e atua nos grupos de pesquisa Educação Pública Brasileira e Política e Sociologia da Educação. 